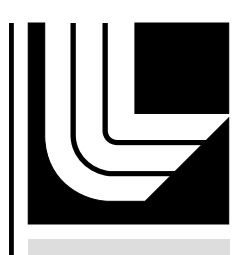

LAW RENCE LIVERMORE N A T IO N A L LABORATORY

\title{
Alternate Alpha Induced Reactions for NIF Radiochemistry
}

D. A. Shaughnessy, K. J. Moody, L. A. Bernstein

March 2, 2010 
This document was prepared as an account of work sponsored by an agency of the United States government. Neither the United States government nor Lawrence Livermore National Security, LLC, nor any of their employees makes any warranty, expressed or implied, or assumes any legal liability or responsibility for the accuracy, completeness, or usefulness of any information, apparatus, product, or process disclosed, or represents that its use would not infringe privately owned rights. Reference herein to any specific commercial product, process, or service by trade name, trademark, manufacturer, or otherwise does not necessarily constitute or imply its endorsement, recommendation, or favoring by the United States government or Lawrence Livermore National Security, LLC. The views and opinions of authors expressed herein do not necessarily state or reflect those of the United States government or Lawrence Livermore National Security, LLC, and shall not be used for advertising or product endorsement purposes.

This work performed under the auspices of the U.S. Department of Energy by Lawrence Livermore National Laboratory under Contract DE-AC52-07NA27344. 
August 7, 2008

Alternate Alpha Induced Reactions for NIF Radiochemistry

D.A. Shaughnessy, K.J. Moody, and L.A. Bernstein

Background:

Radiochemical analysis of NIF capsule residues has been identified as a potential diagnostic of NIF capsule performance. In particular, alpha-induced nuclear reactions that occur on tracer elements added to the NIF capsule have been shown through simulation to be a very sensitive diagnostic for mix. The short range of the alpha particles makes them representative of the hot spot where they are created through the fusion of deuterium and tritium. Reactions on elements doped into the innermost part of the capsule ablator would therefore be sensitive to material that had mixed into the hot spot. Radiochemical determinations of activated detector elements may perhaps be the only true measure of mix that occurs in a NIF capsule, particularly in cases when the capsule fails.

Requirements for Alpha Induced Reactions:

In order to measure alpha particle induced reactions in a NIF capsule, several requirements must be fulfilled. Firstly, since the alpha particle is created with $3.5 \mathrm{MeV}$ of kinetic energy subsequent reactions must not have a threshold that is larger than this energy or else only upscattered alpha particles will participate in reactions with the tracer and there are far fewer $\left(<1 / 10^{\text {th }}\right)$ of these particles. Secondly, the cross-section for the reaction must be large enough such that there will be a measurable amount of reaction product after the shot. It has been estimated that if approximately $10^{8}$ atoms are created then a better than $10 \%$ measurement can be made assuming a $10^{-4}$ collection efficiency. Thirdly, the reaction product must have a half-life that is not so short that it decays before collection. A longer half-life may be possible to measure if short turnaround times are not required between NIF shots or if mass spectrometric methods can be employed. Ideally, the product would emit a characteristic radiation that would be easily visible over the background of interfering reaction products with a convenient decay rate for shorter counting times. In some cases, chemical separations may be used to purify a sample prior to nuclear counting, especially when the reaction product decay cannot be seen over a large background. In order to report absolute numbers of atoms produced during a NIF shot, the collection efficiency must be determined through measurement of a tracer coloaded with the detector element in the same part of the capsule. This means that an appropriate tracer must be available, eliminating reaction products where the corresponding tracer is too short-lived to allow it to be placed inside the capsule prior to the shot. Lastly, there must be a method for placing the detector element at the desired location in the desired well-characterized amount in the inner most part of the ablator. This list of requirements results in only a few possible alpha induced reactions that could possibly be used as a mix diagnostic in NIF point-design capsules. 
${ }^{18} \mathrm{O}(\alpha, \mathrm{n}){ }^{21} \mathrm{Ne}$ : Issues with chamber backgrounds may make this measurement extremely difficult. It has the largest cross section of any of the potential alpha reactions (approximately $260 \mathrm{mb}$ at $3.5 \mathrm{MeV}$ ). Oxygen is ubiquitous throughout the capsule so that loading and subsequently assaying the ${ }^{18} \mathrm{O}$-content of the innermost layer of the ablator will be an issue. Enriched ${ }^{18} \mathrm{O}$ will have to be co-loaded with ${ }^{22} \mathrm{Ne}$ as the tracer of the recovery fraction. A capsule that produces $200 \mathrm{~kJ}$ of yield results in more than $5 \times 10^{7}$ atoms of ${ }^{21} \mathrm{Ne}$ produced from $2.7 \times 10^{15}$ atoms of ${ }^{18} \mathrm{O}$ initially loaded in the ablator. In reality, the number of oxygen atoms in the capsule would probably be much higher, but they would be located throughout the capsule and not just at the ice-ablator interface. The product is a stable isotope, which means that mass spectrometric methods would have to be employed for post-shot analysis. Currently, the laboratory does not have a noble gas mass spectrometer that could be used for analysis of these samples. The ${ }^{21} \mathrm{Ne}$ would be collected with the radiochemistry gas collection system already in production. However, precision measurements of the ${ }^{21} \mathrm{Ne}$ produced are difficult to perform due to the large ${ }^{21} \mathrm{Ne}$ background present in the target chamber. This is discussed in more detail in Ken Moody's document titled "An Evaluation of the ${ }^{18} \mathrm{O}(\alpha, \mathrm{n})^{21} \mathrm{Ne}$ Mix Diagnostic".

${ }^{19} \mathrm{~F}(\alpha, \mathrm{n}){ }^{22} \mathrm{Na}$ : The Q-value of $-1.95 \mathrm{MeV}$ and Coulomb barrier of $\mathrm{E}_{\mathrm{th}}=2.0 \mathrm{MeV}$ make this a possible candidate for alpha reactions. Scaling the cross section to that of the ${ }^{18} \mathrm{O}$ reaction for the same $200 \mathrm{~kJ}$ shot, $1.3 \times 10^{6}$ atoms of ${ }^{22} \mathrm{Na}$ would be produced from the same number of ${ }^{19} \mathrm{~F}$ atoms compared to ${ }^{18} \mathrm{O}$. The ${ }^{22} \mathrm{Na}$ product has a characteristic gamma ray at $1275 \mathrm{keV}$ and also decays via positron emission with a half-life of 2.6 years. This longer half-life would require longer counting times before results were available. The sodium would be traced with either 15 -hour ${ }^{24} \mathrm{Na}$, making capsule fabrication more challenging, or with ${ }^{27} \mathrm{Al}$ (producing ${ }^{24} \mathrm{Na}$ in situ via the (n, $\left.\alpha\right)$ reaction). The possibility of loading fluorine into the capsule has not yet been examined. Sodium reaction products require solid collection capability. The background may be questionable as sodium may be ubiquitous throughout the target chamber. ${ }^{22} \mathrm{Na}$ could also be produced in the ${ }^{22} \mathrm{Ne}(\mathrm{d}, 2 \mathrm{n})^{22} \mathrm{Na}$ and ${ }^{22} \mathrm{Ne}(\mathrm{p}, \mathrm{n})^{22} \mathrm{Na}$ reactions as well as the ${ }^{23} \mathrm{Na}(\mathrm{n}, 2 \mathrm{n}){ }^{22} \mathrm{Na}$ reaction, which means that neon and sodium would have to be excluded from the target and chamber to eliminate competing background reactions. This will be extremely difficult based on current estimates of the neon background and the presence of sodium in the chamber.

${ }^{10} \mathrm{~B}(\alpha, \mathrm{n}){ }^{13} \mathrm{~N}$ : This reaction has a positive Q-value of $1.1 \mathrm{MeV}$ and a threshold of $<2.0$ $\mathrm{MeV}$. For a $200 \mathrm{~kJ}$ shot, the production of ${ }^{13} \mathrm{~N}$ scaled to the ${ }^{18} \mathrm{O}$ reaction would be $1.3 \times 10^{7}$ atoms. It is unknown at this time if the resulting nitrogen would be present as a gas or solid (or possibly both). The possibility of placing boron in the capsule has not yet been explored. The ${ }^{13} \mathrm{~N}$ product is a pure positron emitter with a 10 -minute half-life. As we do not yet know the time constant for removing reaction products from the chamber, this short half-life cannot be excluded at this time, although it means that the chemical form of the product nitrogen must be known a priori. ${ }^{13} \mathrm{~N}$ could also be made from deuteron reactions on carbon (both naturally occurring isotopes ${ }^{12} \mathrm{C}$ and ${ }^{13} \mathrm{C}$ ) resulting in a potentially large background correction since carbon will be ubiquitous in the NIF chamber. If the capsule were loaded with both isotopes of Boron $\left({ }^{10} \mathrm{~B}\right.$ and $\left.{ }^{11} \mathrm{~B}\right)$ and the ${ }^{13} \mathrm{~N}$ collected in the form of $\mathrm{CN}$ then it could be traced through measurement of the ${ }^{11} \mathrm{C}$ 
from ${ }^{11} \mathrm{~B}(\mathrm{p}, \mathrm{n}){ }^{11} \mathrm{C}$. The resulting ratio of ${ }^{13} \mathrm{~N}$ vs. ${ }^{11} \mathrm{C}$ would provide a $14 \mathrm{MeV}$ neutron (i.e., yield) normalized measurement of the $(\alpha, n)$ reaction. This approach is highly uncertain since the chemical composition of the ${ }^{13} \mathrm{~N}$ collected remains unclear.

${ }^{29} \mathrm{Si}(\alpha, \mathrm{p}){ }^{32} \mathrm{P}$ : The Q-value for this reaction is $-2.45 \mathrm{MeV}$ and the Coulomb barrier is $\mathrm{E}_{\mathrm{th}}=2.5 \mathrm{MeV}$, making this another possible candidate. The ${ }^{32} \mathrm{P}$ is a pure beta emitter with a 14-day half-life and an endpoint energy for decay of $1.7 \mathrm{MeV}$. Chemical separation and sample preparation will be required before a post-shot sample could be analyzed. A scaled $200 \mathrm{~kJ}$ shot would produce roughly $1.2 \times 10^{7}$ atoms of ${ }^{32} \mathrm{P}$. Phosphorous would require solid collection, with beta-emitting, 25 -day ${ }^{33} \mathrm{P}$ used as the yield tracer (endpoint energy $=0.35 \mathrm{MeV}$ ) Difficulty will arise here from determining the $\beta$-background from other reaction products, such as uncollected tritium and other trace elements in the capsule such as $\mathrm{Mg}, \mathrm{Si}, \mathrm{Mn}, \mathrm{Al}, \mathrm{Fe}$ and $\mathrm{Ni} .{ }^{30} \mathrm{Si}$ present in the capsule and surrounding chamber will also undergo $(\alpha, p)$ reactions to form ${ }^{33} \mathrm{P}$. If significant ${ }^{33} \mathrm{P}$ is produced, it will eliminate the use of ${ }^{33} \mathrm{P}$ as a collection efficiency tracer. In addition, decay curve analysis over the course of several days of counting would be required to differentiate between the ${ }^{32} \mathrm{P}$ and ${ }^{33} \mathrm{P}$ beta particles, which means that this reaction would require a longer delay time between shots. Background would be produced from neutron capture reactions on naturally occurring phosphorous and $(n, p)$ reactions on naturally occurring sulfur.

Summary:

There are several possible alpha-induced reactions that could be used as an indicator of mix in a NIF capsule. Each one has experimental challenges that can be overcome once the selection of the preferred reaction has been made. With careful design of the capsule and the surrounding environment in the NIF chamber, background from interfering nuclear reactions can be avoided resulting in a cleaner radiochemical signal. While the ${ }^{21} \mathrm{Ne}$ and possibly ${ }^{13} \mathrm{~N}$ will be collected with gas collection, the most likely candidates for alpha-induced reactions will ultimately require the implementation of a solid collection scheme. 